\title{
OCCURRENCE PATTERNS AND POPULATION DENSITY OF BARKING DEER (MUNTIACUS VAGINALIS) IN THE SOUTHERN SLOPES OF HIMALAYA FOOTHILLS, PUNJAB, PAKISTAN
}

\author{
U. Habiba ${ }^{1,2,3}$, M. Anwar ${ }^{1}$, R. Khatoon ${ }^{1}$, B. M. Khan ${ }^{3}$ and K. A. Nasir ${ }^{4}$ \\ ${ }^{1}$ Department of wildlife Management, PMAS, Arid Agriculture University Rawalpindi, Pakistan \\ ${ }^{2}$ Division of Biological Sciences, University of Montana 32 Campus Drive Missoula, MT 59812 \\ ${ }^{3}$ Department of Forestry and Wildlife Management, University of Haripur, Haripur \\ ${ }^{4}$ Department of Botany, University of Swat, Swat \\ Corresponding author: Ume Habiba, ume.habiba8@gmail.com,
}

\begin{abstract}
Barking deer is a small-sized cervid mammal and in Pakistan its population are limited to outer Himalayan foothill forests of Punjab Pakistan. They are usually associated with low but dense thorn scrub of Acacia modesta, Olea ferruginea and Zizyphus nummularia. Occupancy modelling was used to assess how environmental factors influence occurrence probabilities. The population parameters of barking deer were examined in Murree, Kotli-Sattian and Kahuta National Parks through direct visual observations and indirect signs of animal from 2015-2017. To estimate population density, distance sampling of the line transect data was employed. Mean population density was 0.27 individuals $/ \mathrm{km}^{2}$. The range of encounter rates in each study site was 0.04 to 0.43 per $\mathrm{km}$ of transect. Population density in summer was higher $\left(0.43 / \mathrm{km}^{2}\right)$ than in winter $\left(0.36 / \mathrm{km}^{2}\right)$, possibly due to the addition of new-borns in May. The barking deer is basically a solitary animal. This species is endangered in Pakistan and its population are declining. Conservation efforts with focus on protection of disturbance-free habitat for barking deer are recommended in the study area.
\end{abstract}

Key words: Barking deer, Murree, Kotli Sattian Kahuta National Park, Occupancy modelling, Occurrence patterns, Population density.

\section{INTRODUCTION}

Barking deer or northern red muntjac (Muntiacus vaginalis) is a nocturnal species and is difficult to study in field. It hides itself in dense scrub habitat and visits clear open areas for feeding or drinking water (Anonymous 2007a, 2007b). This might be the reason the species remained least studied in wild habitat (Kurt, 1981).

Barking deer is confined to Himalayan foothills zones where there are remnants of tropical dry deciduous forests and Margalla Hills. This species is associated with dense vegetation, particularly Acacia modesta and Olea ferruginea with an understory of Zizyphus mauritiana and Carissa opaca. In Pakistan, the species neither ascends above $1200 \mathrm{~m}$ height nor associated with tropical pine forest zones (Roberts, 1997).

Barking deer is usually solitary except during the rutting season and when juveniles accompany their mothers. According to Dinerstein (1979), individual movements during an entire year can be limited to an area of less than one $\mathrm{km}^{2}$. The average home range is estimated to be $4-5 \mathrm{~km}^{2}$, but may vary depending on the availability of food and the complexity of the environment (Chaplin, 1977).
Population density estimates in barking deer have been highly variable as in Nepal their density was reported $6.7-7.0 / \mathrm{km}^{2}$ (Seidensticker, 1976; Dinerstein, 1980), while in Sri Lanka it was $0.5-7.0 / \mathrm{km}^{2}$ (Barrette, 1977). A survey conducted by Hameed et al. (2009) in Margalla Hills National Park (MHNP) during MarchApril 2005 suggested density of barking deer as $1.21 \pm$ $0.14 / \mathrm{km}^{2}$.

Barking deer abundance varies across regions. Chaplin (1977) reported the presence of more than 200 barking deer distributed over a few hundred hectares of woodland. About 20-30 individuals were estimated by Roberts (1977) from Margalla Hills National Park in northern Pakistan. Hameed et al. (2009) reported that there were 86 individuals distributed on the southern slopes of MHNP. A total population of 45 animals were estimated in Pir-Lasorha National Park (PLNP) (Zulfiquar et al., 2011). The population of barking deer has declined by more than $10 \%$ in the last 10 years and is expected to decrease $>10 \%$ in the next 10 years (Sheikh and Molur, 2005).

Murree, Kotli-Sattian and Kahuta is newly established national park and there is scanty of baseline data regarding diversity, vegetation, habitat and population density of various wild species. Barking deer is endangered in Pakistan and its management and 
conservation require baseline data. Present study was therefore, planned to provide baseline data for management of barking deer in study area.

\section{MATERIALS AND METHODS}

Study Area: This study was conducted in Murree, Kotli Sattian and Kahuta national park located in Rawalpindi district of Pakistan with three subdivisions ("Tehsils"): Murree, Kotli Sattian and Kahuta, comprising a total area of 57581 ha. This district is situated on the southern slopes of the north-western extremities of the Himalayas, including valleys separated by large mountainous tracts. This National Park was declared in 2009 under the Punjab Wildlife Act (Protection, Preservation, Conservation and Management) (amendment), 2007.

Barking deer inhabit tropical dry deciduous forests at an elevation of 600 - $1000 \mathrm{~m}$ (Roberts, 1997). The geology is mostly sedimentary and soil erosion is high, especially in heavily grazed or deforested areas (Ashraf, 1967). Climate of the area can be described as sub-humid, sub-tropical and continental in the south changing to humid, sub-tropical and continental in the north. Mean winter temperatures range from $1.6-21^{\circ} \mathrm{C}$. During the summer, temperature may rise to $40.2^{\circ} \mathrm{C}$ (Jilani, 1990). Average annual rainfall is 1,249 $\mathrm{mm}$ and rains are more frequent during monsoon season. The driest month is November with an average rainfall of 16 $\mathrm{mm}$ (GoP, 2006).

Other mammal species in study area include leopard (Panthera pardus), jungle cat (Felis chaus), rhesus monkey (Macaca mulatta), masked palm civet (Paguma larvata), yellow-throated marten (Martes flavigula), small Kashmir flying squirrel (Eoglaucomys fimbriatus), wild boar (Sus scrofa), Eurasian otter (Lutra lutra), red fox (Vulpes vulpes griffithi), and golden jackal (Canis aureus). Many of these species are threatened by over-exploitation, destruction and fragmentation of habitat, and other pressures (EPD Punjab, 2010).

Study Design: Extensive field surveys were conducted in different parts of Murree, Kotli Sattian and Kahuta National Park from August 2015 to November 2017. Furthermore, faecal pellets, footprints, and voice calls were also observed to maximize the chances to locate the animal. Twenty-four sites were randomly selected depending upon the extent of area used by the barking deer and were considered as sampling units for this study.

Line transect method was used to survey barking deer in each site. Transects were along regularly utilized walking paths by local people. As much as possible, transect lines passed through all types of microhabitats. Transects were randomly positioned and orientated in each of the 24 study sites (Table 1). A hand-held GPS unit (Garmin Summit, Kansas, USA) was used to locate the starting points of transects. Three small transects of different length were run in each study site. The length and width of each transect was selected on the basis of the conditions of the study site and the density of the forest.

Transect lines were walked early in the day (beginning about thirty minutes before dawn and in the evening (about 30 minutes before sunset). When direct or indirect sign was detected, the perpendicular distance (metres) from the transect line to the centre of the sign was recorded (Fig 1). The observed individuals were classified as infants, juveniles, sub-adults or adults (over $45 \mathrm{~cm}$ in height) follwing Pokharel and Chalise, 2010.

Table 1. Encounter rate of direct and indirect signs of barking deer in Murree, Kotli-Sattian and Kahuta National Park during 2015-2017.

\begin{tabular}{|c|c|c|c|c|c|c|c|c|}
\hline S.No. & study sites & $\begin{array}{l}\text { Extent of } \\
\text { human use }\end{array}$ & $\begin{array}{c}\text { Length } \\
(\mathbf{k m})\end{array}$ & $\begin{array}{c}\text { Encounter } \\
\text { rate of } \\
\text { animals } \\
\text { (per km) }\end{array}$ & $\begin{array}{c}\text { Encounter } \\
\text { rate of } \\
\text { faecal } \\
\text { pellets } \\
\text { (per km) }\end{array}$ & $\begin{array}{l}\text { Encounter } \\
\text { rate of foot } \\
\text { prints (per } \\
\text { km) }\end{array}$ & $\begin{array}{l}\text { Encounter } \\
\text { rate of call } \\
\text { records } \\
\text { (per } \mathbf{k m})\end{array}$ & $\begin{array}{c}\text { Mean } \\
\text { encounter } \\
\text { rate }\end{array}$ \\
\hline 1 & Kathar & High & 5 & 0.4 & 0.07 & 0.17 & 0.0 & 0.16 \\
\hline 2 & Baroha & Low & 8 & 0.25 & 0.12 & 0.03 & 0.07 & 0.12 \\
\hline 3 & Benghal & Low & 4 & 0.29 & 0.15 & 0.26 & 0.07 & 0.19 \\
\hline 4 & Salgran & Moderate & 3 & 0.0 & 0.22 & 0.17 & 0.0 & 0.10 \\
\hline 5 & Angoori & Moderate & 6 & 0.0 & 0.10 & 0.0 & 0.05 & 0.04 \\
\hline 6 & Numble & Low & 6 & 0.0 & 0.07 & 0.08 & 0.04 & 0.05 \\
\hline 7 & Simli & Low & 6 & 0.4 & 0.09 & 0.09 & 0.0 & 0.15 \\
\hline 8 & Phaphril & High & 4 & 0.5 & 0.15 & 0.22 & 0.0 & 0.22 \\
\hline 9 & Gura & Low & 8 & 0.14 & 0.04 & 0.09 & 0.0 & 0.07 \\
\hline 10 & Thoa & Low & 7 & 0.83 & 0.11 & 0.24 & 0.1 & 0.32 \\
\hline 11 & Slamber & Moderate & 8 & 0.13 & 0.10 & 0.08 & 0.04 & 0.09 \\
\hline 12 & Keral & Low & 4 & 0.24 & 0.11 & 0.07 & 0.17 & 0.15 \\
\hline 13 & Dalatar & Low & 6 & 0.14 & 0.32 & 0.16 & 0.10 & 0.18 \\
\hline
\end{tabular}




\begin{tabular}{lllllllcl}
\hline 14 & Beor & Moderate & 5 & 0.25 & 0.11 & 0.08 & 0.0 & 0.11 \\
15 & Seri & Low & 6 & 0.33 & 0.07 & 0.07 & 0.06 & 0.13 \\
16 & Sang & Low & 4 & 0.67 & 0.07 & 0.19 & 0.0 & 0.23 \\
17 & Khalol & Moderate & 4 & 1.35 & 0.11 & 0.17 & 0.08 & 0.43 \\
18 & Narh & High & 4 & 0.20 & 0.19 & 0.08 & 0.0 & 0.12 \\
19 & Badnian & Low & 4 & 0.0 & 0.17 & 0.32 & 0.0 & 0.12 \\
20 & Makrosh & Moderate & 4 & 0.0 & 0.38 & 0.22 & 0.22 & 0.21 \\
21 & Thun & Low & 4 & 0.4 & 0.07 & 0.18 & 0.11 & 0.19 \\
22 & Santh Sarula & Low & 3 & 0.0 & 0.07 & 0.0 & 0.07 & 0.04 \\
23 & Santh & Low & 7 & 0.4 & 0.08 & 0.08 & 0.03 & 0.15 \\
& Anwali & & & & & & & \\
24 & Chakka & High & 5 & 0.0 & 0.17 & 0.06 & 0.11 & 0.09 \\
& Total & & 6.92 & 3.14 & 3.11 & 1.32 & 3.62 \\
\hline
\end{tabular}

Data Analysis: Occupancy modelling in R (version 3.3.2) was used to assess how occurrence probabilities varied with environmental factors (MacKezie et al., 2002).

The models assume that sites are closed to births, deaths, immigration, and emigration over the survey period (MacKenzie et al., 2006). Five hypotheses were developed to explain the effects of landscape characteristics on the probability of occurrence $(y)$ and the probability of detection (p). Hypotheses were developed based on factors that were potentially related to the species' life history. Each hypothesis was expressed as a model and each model included the influence of various characteristics (covariates) (Table 2).

The NULL MODEL included no occupancy covariates and represented the hypothesis that occupancy probability is not influenced by any of the factors measured. Sampling effort was included as a covariate for every model because we assumed that it would have a meaningful effect on detection rates. Sample effort was the number of days spent in the field survey during a given survey period.

Table 2. Estimates for occupancy probability (y), detection probability (p) and covariates.

\begin{tabular}{clcccc}
\hline Parameter & AICc & $\boldsymbol{\beta}$ estimate & SE & LCI & UCI \\
\hline Null Model & 445.5185 & & & & \\
y intercept & & 9.53 & 17.2 & 0.553 & 0.58 \\
$p$ intercept & & -0.426 & 0.113 & -3.77 & 0.00016 \\
Effect of elevation & 447.5204 & & & & \\
y intercept & & 9.313 & 15.9 & 0.5859 & 0.558 \\
Elevation & & 0.579 & 16.8 & 0.0345 & 0.972 \\
$p$ intercept & & -0.426 & 0.113 & -3.77 & 0.000161 \\
Habitat features & 448.2267 & & & & \\
y intercept & & 10.87 & 38.1 & 0.2856 & 0.775 \\
Tree Cover & & -1.33 & 54.5 & -0.0243 & 0.981 \\
$p$ intercept & & -0.431 & 0.113 & -3.81 & 0.000139 \\
Coordinates & -0.131 & 0.116 & -1.14 & 0.256143 \\
Habitat landscape & 449.4855 & & & & \\
y intercept & & 11.04 & 45.1 & 0.2446 & 0.807 \\
Tree Cover & & -1.68 & 72.7 & -0.0231 & 0.982 \\
$p$ intercept & & -0.4274 & 0.1130 .116 & -3.773 & 0.000161 \\
Elevation & & 0.0193 & & 0.167 & 0.867344 \\
Habitat characteristics & 449.4859 & & & & \\
y intercept & & 11.1 & 40.2 & 0.2760 & 0.783 \\
elevation & & 1.0 & 32.9 & 0.0305 & 0.976 \\
$p$ intercept & & -0.4274 & 0.113 & -3.774 & 0.000161 \\
coordinates & & 0.0192 & 0.116 & 0.166 & 0.867958 \\
\hline
\end{tabular}

*Standard errors (SE), lower (LCI) and upper (UCI) 95\% confidence intervals.

Five models were fit to the detection-non detection data using occupancy analysis in package Unmarked (Version 0.12-2). We used model selection techniques to classify models (Burnham and Anderson, 2002; MacKenzie et al., 2006) and used goodness-of-fit testing to assess the probability of obtaining the observed 
data within the simulated distribution of data (Mackenzie and Bailey, 2004).

To estimate population density, distance sampling of the line transect data was used through DISTANCE 7.1 (Laake et al., 1998). The density of individuals in the study zone is assessed by the following equation (Buckland et al., 1993).

$\mathrm{D}=\underline{\mathrm{n} \times \mathrm{f}(0)}$

$$
2 \mathrm{~L}
$$

Where

$\mathrm{D}=$ density per $\mathrm{km}^{2}$

$\mathrm{n}=$ Number of detected objects.

$\mathrm{f}(0)=$ probability of density
$\mathrm{L}=$ total length of linear transects.

We analysed different models of $\mathrm{f}(0)$, namely uniform cosine and uniform-single-polynomial (Buckland et al. 1993). Models were selected to have a minimum Akaike Information Criterion (AIC) value and a small variance (Marques et al., 2001) (Table 3).

We used t-test to verify that the frequency of observations during the morning sessions was comparable to that of the evening sessions. Chi-square test was used to assess difference in naive and estimated mean population densities. Correlation was applied to analyse relationship between the population density and level of disturbance.

Table 3. Model selection based on estimates of AIC and likelihood for habitats of barking deer in Murree, Kotli Sattian and Kahuta national park.

\begin{tabular}{|c|c|c|c|c|c|c|c|}
\hline $\begin{array}{l}\text { Model } \\
\text { No. }\end{array}$ & Model & AIC & parameters & Likelihood & f (0) & $\operatorname{SE}\{\mathbf{f}(0)\}$ & $\begin{array}{l}\% \\
\text { CV }\end{array}$ \\
\hline M 01 & CDS half normal-cosine & 977.80 & 5 & -524.39207 & 0.2921 & 0.3878 & 13.28 \\
\hline M 02 & $\begin{array}{c}\text { CDS Hazard rate -simple } \\
\text { polynomial }\end{array}$ & 979.23071 & 3 & -504.65148 & $0 \cdot 7303$ & $0 \cdot 0541$ & $17 \cdot 41$ \\
\hline M 03 & CDS uniform-cosine & 989.24774 & 5 & -500.31339 & 0.9431 & $0 \cdot 1579$ & $16 \cdot 75$ \\
\hline М 04 & $\begin{array}{l}\text { CDS half normal- hermite } \\
\text { polynomial }\end{array}$ & 1006.9746 & & -485.61536 & $0 \cdot 6914$ & $0 \cdot 0283$ & $24 \cdot 09$ \\
\hline M 05 & CDS hazard rate-cosine & 1013.3030 & 7 & -483.89771 & 0.7212 & 0.3029 & 35.62 \\
\hline M 06 & MA & 1017.8839 & 2 & -439.4812 & $0 \cdot 3694$ & $0 \cdot 0397$ & $36 \cdot 23$ \\
\hline M 07 & $\begin{array}{l}\text { MCDS Hazard rate- simple } \\
\text { polynomial }\end{array}$ & 1050.7842 & 3 & -384.6572 & 0.987 & $0 \cdot 1579$ & $42 \cdot 75$ \\
\hline M 08 & MCDS Half normal-cosine & 1053.0746 & 4 & -487.45963 & 0.6913 & $0 \cdot 0341$ & $48 \cdot 93$ \\
\hline M 09 & MCDS Hazard rate- cosine & 1148.6723 & 5 & -434.7454 & 0.543 & $0 \cdot 6022$ & 58.34 \\
\hline M 10 & DSM & 1165.784 & 5 & -438.05787 & 0.645 & $0 \cdot 0217$ & 63.76 \\
\hline
\end{tabular}

\section{RESULTS}

A total of 80 surveys were conducted. Barking deer were detected in 17 out of 24 (71\%) study sites. Mean encounter rate was 3.62 in the overall study area (Table 1). The mean encounter rate of each study site was recorded from 0.04 to 0.43 (Table 4).

Encounter rate was higher in summer than in winter (Table 5). Encounter rates of barking deer were highest during the rut (i.e. in October followed by
September). We encountered more females than males (Table 5).

Occurrence Models: Model selection for barking deer occurrence involved some uncertainty because there were no higher differences in AIC values among the models. The top ranking model was the null model, although the elevation model also received relatively strong support. In the elevation model, increasing elevation had a positive influence on barking deer occurrence and a negative influence on barking deer detection (Table 2). Overall occupancy of barking deer in the study area was $100 \%$ and detection probability was $40 \%$.

Table 4. Estimates of barking deer abundance (N) and density (D) with $95 \%$ confidence intervals (CI) and percentage coefficient of variation $(\% \mathrm{CV})$.

\begin{tabular}{lccccccc}
\hline Model & N & 95\% CI for N & D/km & 95\% CI for D & \%CV & $\begin{array}{c}\text { Detection } \\
\text { probability }\end{array}$ & $\begin{array}{c}\text { Encounter } \\
\text { rate }\end{array}$ \\
\hline M01 & 43 & $23.4-78.6$ & 0.24 & $0.185-0.857$ & $57 \cdot 62$ & 1.7 & 99.6 \\
M02 & 54 & $43.1-97.5$ & 0.36 & $0.193-0.576$ & $11 \cdot 91$ & 1.4 & 98.3 \\
M03 & 48 & $26.4-73.7$ & 0.29 & $0.127-0.985$ & 11.69 & 1.3 & 85.8 \\
M04 & 67 & $52.8-107.4$ & 0.43 & 0.3231 .676 & 17.09 & 0.93 & 67.10 \\
M05 & 69 & $56.7-195.2$ & 0.81 & $0.127-0.986$ & 28.72 & 0.60 & 78.3 \\
\hline
\end{tabular}




\begin{tabular}{lccccccc}
\hline M06 & 76 & $72.3-127.8$ & 0.84 & $0.451-0.932$ & 13.98 & 0.88 & 60.2 \\
M07 & 105 & $57.1-166.7$ & 1.17 & $0.812-10.75$ & 9.15 & 0.82 & 68.76 \\
M08 & 97 & $47.3-187.74$ & 0.76 & $0.19-13.73$ & $22 \cdot 64$ & 0.59 & 89.37 \\
M09 & 103 & $76.54-139.3$ & 0.59 & $0.311-0.861$ & 1.000 & 0.474 & 72.26 \\
M10 & 116 & $85.22-126.8$ & 0.81 & $0.132-0.950$ & $14 \cdot 67$ & 0.97 & 92.45 \\
\hline
\end{tabular}

Table 5. Individual composition of barking deer in Murree, Kotli Sattian and Kahuta national park during different months of 2015-2017.

\begin{tabular}{lccccc}
\hline Month & Male & Female & Fawn & Fawn/Female & Male/female \\
\hline September & 2 & 2 & 1 & 0.5 & 1 \\
October & 4 & 5 & 2 & 0.4 & 0.8 \\
November & & 1 & - & - & - \\
December & - & - & - & - & - \\
January & 2 & 1 & - & - & 1 \\
February & 1 & 3 & - & 0 & 0.33 \\
March & 1 & 2 & 1 & - & 0.5 \\
April & 1 & - & - & - & - \\
May & - & - & - & - & - \\
June & - & - & - & - & 0.67 \\
July & - & 3 & 1 & 0.33 & 0.72 \\
August & 2 & 17 & 5 & 0.43 & - \\
Total & 13 & & & & - \\
\hline
\end{tabular}

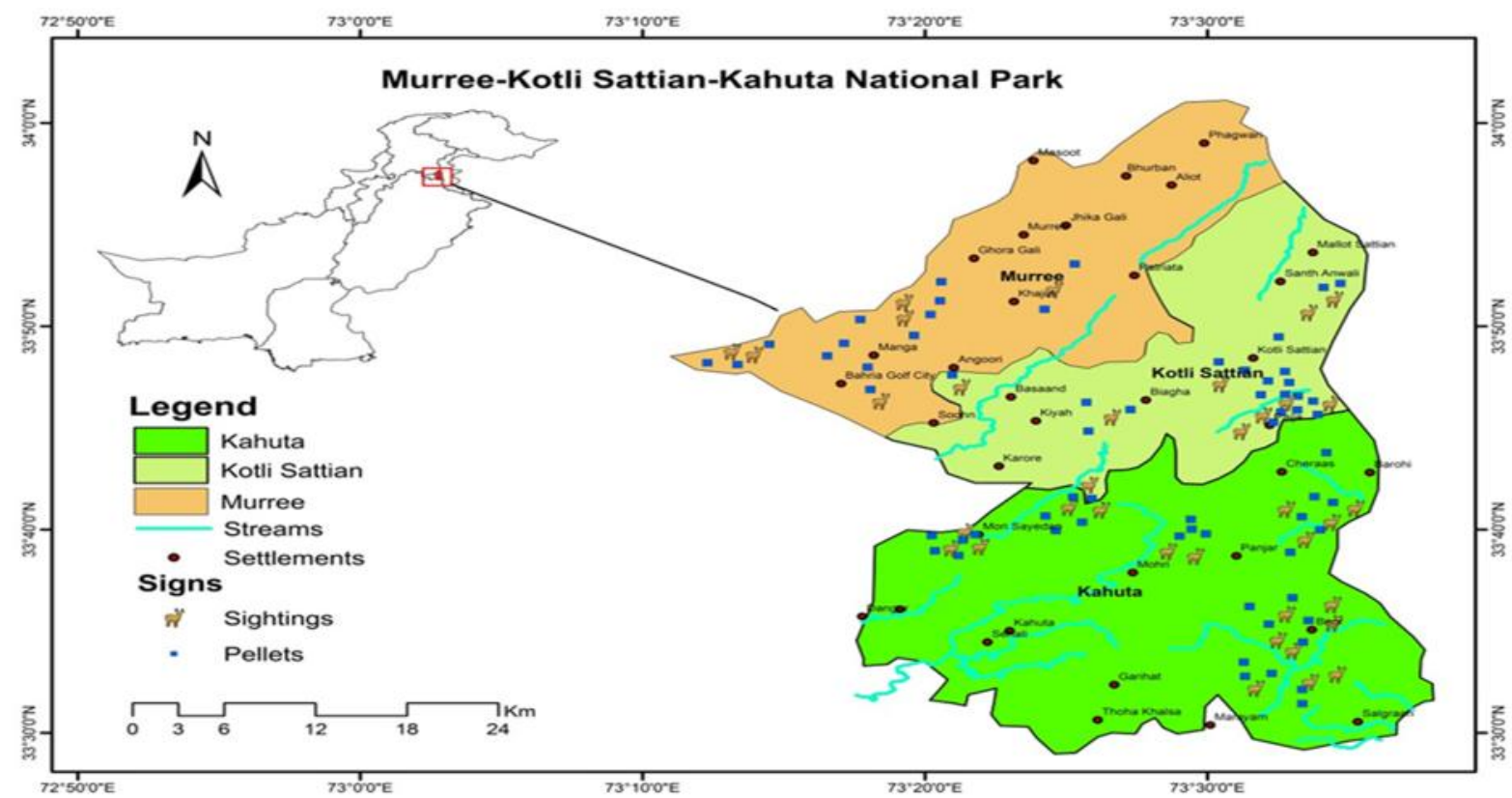

Fig 1. Distribution map of barking deer in Murree, Kotli Sattian and Kahuta national park.

Source: Snow Leopard Foundation (SLF).

Population Density: Average population density of barking deer was estimated $0.27 / \mathrm{km}^{2}$. Chi-square test revealed that there was no difference between naive $(0.40$ $\left./ \mathrm{km}^{2}\right)$ and estimated mean population density $\left(\chi^{2}=20.00\right.$, $\mathrm{df}=4, \mathrm{P}>0.05)$. Seasonal variations in population density of the animal were also recorded and it was higher (0.43/ $\left.\mathrm{km}^{2}\right)$ during summer than $\left(0.36 / \mathrm{km}^{2}\right)$ winter.
Group Size: Mostly single animal was directly observed in $40 \%$ cases and maximum group size was two which was observed in $31 \%$ cases in the study area. Groups of two animals were observed more in summer $(60 \%)$ than in winter $(40 \%)$. Group size was also correlated with habitat disturbance, results of regression showed that group size is not significantly different from each other. Groups of two animals were observed in undisturbed 
areas more often than in areas with livestock $\left(\mathrm{r}^{2}=0.77, \mathrm{p}\right.$ $=0.075$ )

Sex and Age Structure: The observed sex ratio was biased towards females (male / female ratio $=0.72, \chi^{2}=$ 12.32, $\mathrm{df}=1, \mathrm{p}<0.001$; Table 5 ). The ratio of sub-adults to females was 0.43 . The number of fawns per female was higher during February and April (0.5), followed by October (0.4) and August (0.33) (Table 5).

\section{DISCUSSION}

The present research study suggested that encounter rate was higher in the morning than evening. Pokharel and Chalise (2010) described in their study that most barking deer were observed at different altitudes, mainly in the morning around 06:00. Adult and sub-adult muntjacs were seen isolated while dependent infants were associated with mothers.

During present survey, average population density $0.27 / \mathrm{km}^{2}$ of barking deer was calculated in different parts of Murree, Kotli Sattian and Kahuta national park. MHNP and Pir Lasora national park (PLNP), harbours more number of individuals. PLNP and adjacent areas hold a reasonable population density (3.44 $\pm 1.12 / \mathrm{km}^{2}$ ) of the deer (Zulfiquar et al., 2011). MHNP holds a reasonably high density $\left(1.21 \pm 0.14 / \mathrm{km}^{2}\right)$ of this deer species (Hameed et al., 2009). Globally, barking deer has been reported to be present in high densities $(0.5$ - 7.0/ km2) in Wilpattu national park, Sri Lanka; (Barrette, 1977) and Nepal (6.7 - 7.0/ $\mathrm{km}^{2}$ ) (Seidensticker, 1976; Dinerstein 1980).

DISTANCE Software model analysis showed a total of 48 deer present in Murree, Kotli Sattian and Kahuta National Park. Chaplin (1977) reported the presence of more than 200 muntjac distributed over a few hundred hectares in the whole region. An estimate of 86 individuals with the range of $76-96$ has been reported from MHNP (Hameed et al., 2009). Roberts (1977) suggested a population of 20-30 individuals in MHNP based upon information collected from local community. Anwar (1997) recorded 112 barking deer individuals in MHNP based on footprints near water bodies. Barking deer are thought to be present in areas undisturbed by humans and livestock. Non-significant, negative correlation between density and disturbance was recorded during present study. Similarly, at Hemja VDC, the middle of the mountain is widely used by barking deer, as this area has been the least impacted by human activities (Pokharel and Chalise, 2010).

Barking deer mostly live solitary but in breeding season group of 1-2 individuals were observed in study area. All previous studies showed similar results. A study reported by Lekagul and McNeely (1977) suggested that most sightings concerned solitary individuals followed by groups of two, mostly females with a single fawn. The barking deer is basically a solitary animal (Roberts, 1977). 93-94\% (Dinerstein, 1979) and 64.5\% (Barrette, 1977) of sightings have been reported as singles. Eisenberg and Lockhart (1972) estimated that juveniles not always accompany females on foraging trips, mostly remained hidden under rocks.

Hameed et al. (2009) analysed herd composition and suggested that $64.3 \%$ of the population was dispersed as singles (males or females) and $35.7 \%$ in groups of two individuals. In $10 \%$ of these groups, females grazed with a female while in $20 \%$ groups, the female was accompanied by a male and in the rest (70\%) the female was accompanied by a single fawn. There was no record of more than one fawn with a female or groups of more than two individuals.

Present survey revealed that females outnumber males in the population and these findings are in line with Hameed et al. (2009). Seidensticker (1976) provided data on adult sexual composition of wild ungulates in Nepal and revealed that a higher percentage of females than males were found in all species except the axis deer. There is considerable variation in the adult sex ratio of ungulates, as reported in other areas (Spillett. 1966; Schaller, 1967).

On average fawn to female ratio of 0.43 was recorded during present survey. Hameed et al. (2009) suggested that such low fawn-to-female ratio may indicate a low population size in the MHNP. The data on sex structure suggested a male-to-female ratio of 1:1.45, not significantly different $(\chi 2=1.6531, \mathrm{p}>0.05)$ from a 1:1 sex ratio. However, the available data on the population structure suggested that there were 0.25 fawns to a female in the total deer population of MHNP. This species is slow breeder and single birth is frequent while twins are very rare (Barrette (1977; Lekagul and McNeely 1977; Roberts (1977). Higher predation on fawns may also result in a low fawn-to-female ratio, and there are indications of a recent increase in the local population of leopards in MHNP (Hameed et al., 2009). In contrast, Wilpattu National Park, Sri Lanka had a much higher fawn to female ratio (76 fawn : 100 females) (Barrette, 1977).

Conclusion: Barking deer is a shy small-sized mammal, limited to few areas of its distribution in outer Himalayan foothill forests of the Punjab. The population density of barking deer in Murree, Kotli Sattian and Kahuta National Park was recorded 0.27 individuals / $\mathrm{km}^{2}$. Population density in summer was recorded higher as compared to winter season due to the addition of newborns in May. More individuals were observed in lessdisturbed areas.

Acknowledgements: The project was funded by Pakistan Agricultural Research Council (PARC) Islamabad Pakistan, under Agricultural Linkages Programme (ALP). In particular, special thanks are due to A. Gill, and staff 
of the Punjab Wildlife Department for their assistance in the field work.

\section{REFERENCES}

Anonymous (2007a). Barking deer in Asia, Wildlife Parks in Asia. Available from URL www.wikipidia.com

Anonymous (2007b). World Wildlife Directory. Available from URL www.wikipidia.com

Anwar, M. (1997). Distribution, population status and conservation of barking deer (Muntiacus muntjac) in Margalla Hills National Park. 485-495.

Ashraf, M.A. (1967). Reconnaissance soil survey, Rawalpindi area. General technical report. Soil survey project of Pakistan, Lahore.

Barrette, C. (1977). Some aspects of behavior of muntjacs in Wilpatto National Park. Mammalia 41: 1-34.

Buckland, S.T., D.A. Anderson, K.P. Burnhamand and J.L. Laake (1993). Distance Sampling: Estimating Abundance of Biological Populations. Chapman and Hall, London, U.K.

Burnham, K.P. and D.R. Anderson (2002). Model selection and multimodel inference: a practical information-theoretic approach. Springer-Verlag, New York counts related to observer differences and species detection rates. Auk 120:1168-1179.

Chaplin, R.E. (1977). Deer.Blandford mammal series. Littlehampton Book Services Ltd, 218:

Dinerstein, E. (1979). An ecological survey of Royal Karnali-Bardia Wildlife Reserve, Nepal: II Habitat and animal interactions. Biol. Cons. 16: 5-38.

Dinerstein, E. (1980). An ecological survey of Royal Karnali-Bardia Wildlife Reserve, Nepal: IIIUngulate Population. Biol. Cons. 18: 5-38.

Eisenberg, J.F. and M. Lockhart (1972). An ecological reconnaissance of Wilpattu National Park, Ceylon. Washington. Smithsonian Institution Press.

EPD (Environment Protection Department), Punjab (2010). Murree Biodiversity Park - Baseline Report on Flora. IUCN Pakistan, Islamabad, Pakistan. III pp 28.

GoP (2006). Meteorological data of Rawalpindi from 1931 to 2006. Pakistan Meteorological Department, Regional Meteorological Center, Islamabad.

Hameed, W., F. Abbas and A. Mian (2009). Population features of barking deer (Muntiacus muntjac) in Margalla Hills National Park Pakistan. Pak J Zool. 41: 137-142.

Jilani, G. (1990). Revised working plan for the scrub forest of Rawalpindi district, 1989-90 to 2019-2020. Government of the Punjab, Forest Department, Pakistan.
Kurt, F. (1981). Muntjac deer. In: (D.Grzimek, D.Badrian, R. Herre and M. Jones, eds.) Grzimek's Enclopedia of Mam 'mals. New York. McGrawHill Publishing Company. pp 137-159.

Laake, J.L., J.F. Derry and S.T. Buckland (1998). Distance 3.5. Research Unit for Wildlife Population Assessment, University of St Andrews, U.K.

Lekagul, B. and J.A. McNeely (1977). Mammals of Thailand. Kurusapa Ladprao Press, Bankok, Thailand.

MacKenzie, D.I. and L.L. Bailey (2004). Assessing the fit of site-occupancy models. J Agric Biol Environ Stat. 9: 300-318.

MacKenzie, D.I., J.D. Nichols, G.B. Lachman, S. Droege, J.A. Royle, C.A Langtimm (2002). Estimating site occupancy rates when detection probabilities are less than one. Ecology. 83: 2248.

MacKenzie, D.I., J.D. Nichols, J.A. Royle, K.H. Pollock, J.E. Hines and L.L. Bailey (2006). Occupancy estimation and modeling: inferring patterns and dynamics of species occurence. San Diego, CA: Elsevier.

Marques, F.F.C., S.T. Buckland, D. Goffin, C.E. Dixon, D.L. Borchers, B.A. Mayle and A.J. Peace (2001). Estimating the density of kudu. African J. of Eco. 43: 362-368.

Pokharel, K. and M.K. Chalise (2010). Status and Distribution Pattern of Barking Deer (Muntiacusmuntjak Zimmermann) in Hemja VDC, Kaski. Nepal J. of Sci. and Tech. 11:223228.

Roberts, T.J. (1977). The mammals of Pakistan. Ernest Benn Limited, London and Tonbridge. 361, in press.

Roberts, T.J. (1997). The Mammals of Pakistan. Oxford University Press, Karachi.425, in press.

Schaller, C. (1967). The deer and the tiger. University of Chicago Press.

Seidensticker, J. (1976). Ungulate population in Chitwan valley, Nepal. Biol. Cons. 10: $183-210$.

Sheikh, K.M. and S. Molur (2005). Status and red list of Pakistan's Mammals based on Pakistan's conservation assessment and management plan for mammals. IUCN, Pakistan.

Spillett, J.J. and K.M. Tamang (1966). Wildlife conservation in Nepal. J. of the Bombay Natural History Society. 63: 557-572.

Zulfiquar, S., R.A. Minhas, M.S. Awan and U. Ali (2011). Population and conservation status of barking deer (Muntiacus muntjac) in PirLasorha National Park and other areas of district Kotli, Azad Jammu and Kashmir, Pakistan. Pak j Zool. 43: 993-997. 